\title{
Metaphorical Perceptions of the Academicians Working in the Field of Recreation Regarding the Concept of "Recreation"
}

\author{
Melike Esentaş \\ Correspondence: Melike Esentaş, Manisa Celal Bayar University, Faculty of Sports Sciences, Turkey. \\ Received: August 16, 2018 \\ doi:10.11114/jets.v6i12.3541 \\ Accepted: September 27, $2018 \quad$ Online Published: October 9, 2018 \\ URL: https://doi.org/10.11114/jets.v6i12.3541
}

\begin{abstract}
The purpose of this study is to reveal how the academicians working in the field of recreation conceptualize their ideas about "recreation" through metaphors. Phenomenology being among the qualitative research methods was used in this study. The research population is composed of the academicians working in the field of recreation in different universities of Turkey. Qualitative data collection method via metaphors was used. When metaphors are used to "describe", a situation, event and phenomenon are described as they exist (Yıldırım and Şimşek, 2013). Data from the study were collected by using a semi-structured metaphor form via survey online. The raw data obtained from the study were examined, incomplete or inexpedient ones were excluded and metaphors were modeled by transferring them to the Nvivo 10 program.

As a result of the data obtained, the academicians working in the field of recreation use such concepts as escape, star, giant, happiness, music box, spring air, freedom, traveler, broken chain ring, octopus, life, Aladdin and the magic lamp, sun, a colorful cake with mixed fruit, work potential, a multi-purpose field or saloon, funfair, umbrella, flying carpet, human, Aegean sea, sea, rainbow, water, living, forest, fishing tackle, bridge, time, wind, chameleon, seasons, breath, science, nature and spice while describing the concept of recreation metaphorically. The data obtained after the interviews were then coded under the appropriate themes after being analyzed with the content analysis method. According to the data obtained, it has been found that it has been gathered under 5 (five) themes as "As a Value for Individual and Society", "Serving Needs", "Social Reputation", "Recreate" and "Self- realization". In conclusion, it is observed that the metaphors obtained comply with the recreation theories regarding the metaphorical perceptions of the academicians working in the field of recreation about the "recreation" concept. In order to better understand the concept of recreation, it is recommended to take evaluation results in practical activities.
\end{abstract}

Keywords: recreation, academicians, metaphor

\section{Introduction}

Since there are so many researches or debates about the determination and definition of the theoretical bases of the leisure time concept, it is quite difficult to find a single definition that has been agreed upon by everyone on the concept of recreation (Madrigal, 2006). Recreation is derived from the recretio word which means being innovated and created again (Karaküçük, 1999; 56). Recreation can also be considered as an entertainment and social activity that allows the individual to restructure oneself personally in the sense of a leisure time experience (Brey and Lehto, 2007;161). Recreation includes individuals of all ages and skill levels who are healthy or disabled and it develops in parallel with their tendency of living a happier and higher quality of life (Tütüncü, 2012).

Recreation consists of all sorts of delightsome and joyful activities chosen at will in leisure time, inside or outside an organization, in or out of town, indoors or outdoors, alone or with group and with or without a medium. Activities are usually carried out with a sincere desire coming from inside not from an external force and not having a reward other than itself (Karaküçük, 2008: 69-75). Torkildsen (2005) states that recreational activities exist to increase the social values of individuals.

Recreation which has become a phenomenon has been a routine lifestyle for some societies and it has manifested rapid developments (Aksen, 1984; Öksüz, 2012). Cordes (2013) defines recreation as the meaningful and entertaining leisure time activities participated by the individuals voluntarily.

Metaphors (mental images) are considered to be the tools with which people try to explain incidents, objects and particularly abstract concepts by using different analogies (Cerit, 2008). In other words, metaphors help determining how the concepts desired to be analyzed are perceived by individuals (Rizvanoğlu, 2007). Lakoff \& Johnson (2005) define metaphor as understanding a concept with the perspective of another one. 
In the light of all these definitions, recreation is the whole of activities that enable individuals to voluntarily participate in their leisure time individually or in group by coming out of the monotone life patterns, which increases their motivation and enables them to learn through experience with fun. In this regard, the purpose of this research is to reveal how the academicians working in the field of recreation conceptualize their ideas about "recreation" through metaphors.

\section{Method}

\subsection{Research Model}

Phenomenology being among the qualitative research methods was used in this study. Phenomenology provides auxiliary data to help us reach the phenomenon of which we are aware but we do not have an in-depth and detailed understanding (Yıldırım and Şimşek, 2013).

\subsection{Participants}

The research population is composed of the academicians working in the field of recreation in different universities of Turkey (Table 1).

Table 1. Demographic information of the participants

\begin{tabular}{|c|c|c|c|c|c|c|}
\hline$\overline{\text { Participants }}$ & Sex & Age & $\begin{array}{l}\text { Marital } \\
\text { Status }\end{array}$ & Title & Income & Region \\
\hline$\overline{1}$ & Male & $18-29$ & Single & Res. Assist. & $3001-5000 \mathrm{TL}$ & Aegean Sea \\
\hline 2 & Male & $30-39$ & Married & Dr. Lecturer & $5001 \mathrm{TL}$ and above & Aegean Sea \\
\hline 3 & Male & $30-39$ & Married & Res. Assist. & $3001-5000 \mathrm{TL}$ & Aegean Sea \\
\hline 4 & Male & $40-49$ & Married & Lecturer & $3001-5000 \mathrm{TL}$ & Marmara Region \\
\hline 5 & Male & $30-39$ & Married & Dr. Lecturer & $5001 \mathrm{TL}$ and above & Mediterranean Region \\
\hline 6 & Female & $50+$ & Married & Assoc. Prof. & $5001 \mathrm{TL}$ and above & Mediterranean Region \\
\hline 7 & Male & $40-49$ & Married & Assoc. Prof. & $5001 \mathrm{TL}$ and above & Black Sea Region \\
\hline 8 & Male & $30-39$ & Married & Dr. Lecturer & $5001 \mathrm{TL}$ and above & Central Anatolia Region \\
\hline 9 & Female & $40-49$ & Married & Assoc. Prof. & $5001 \mathrm{TL}$ and above & Black Sea Region \\
\hline 10 & Male & $40-49$ & Single & Assoc. Prof. & $5001 \mathrm{TL}$ and above & Marmara Region \\
\hline 11 & Male & $50+$ & Married & Prof. Dr. & $5001 \mathrm{TL}$ and above & Central Anatolia Region \\
\hline 12 & Female & $18-29$ & Married & Lecturer & $3001-5000 \mathrm{TL}$ & Marmara Region \\
\hline 13 & Male & $18-29$ & Married & Res. Assist. & $5001 \mathrm{TL}$ and above & Central Anatolia Region \\
\hline 14 & Male & $40-49$ & Married & Assoc. Prof. & $5001 \mathrm{TL}$ and above & Central Anatolia Region \\
\hline 15 & Male & $30-39$ & Married & Lecturer & $3001-5000 \mathrm{TL}$ & Central Anatolia Region \\
\hline 16 & Female & $30-39$ & Married & Res. Assist. & $5001 \mathrm{TL}$ and above & Central Anatolia Region \\
\hline 17 & Male & $30-39$ & Married & Assoc. Prof. & $5001 \mathrm{TL}$ and above & Southeastern Anatolia Region \\
\hline 18 & Male & $40-49$ & Married & Assoc. Prof. & $5001 \mathrm{TL}$ and above & Southeastern Anatolia Region \\
\hline 19 & Female & $40-49$ & Married & Assoc. Prof. & $5001 \mathrm{TL}$ and above & Marmara Region \\
\hline 20 & Male & $40-49$ & Married & Assoc. Prof. & $5001 \mathrm{TL}$ and above & Marmara Region \\
\hline 21 & Male & $18-29$ & Single & Res. Assist. & $3001-5000 \mathrm{TL}$ & Aegean Sea \\
\hline 22 & Male & $40-49$ & Married & Dr. Lecturer & $5001 \mathrm{TL}$ and above & Marmara Region \\
\hline 23 & Female & $30-39$ & Married & Dr. Lecturer & $5001 \mathrm{TL}$ and above & Aegean Sea \\
\hline 24 & Female & $30-39$ & Single & Res. Assist. & $3001-5000 \mathrm{TL}$ & Black Sea Region \\
\hline 25 & Female & $40-49$ & Married & Assoc. Prof. & $5001 \mathrm{TL}$ and above & Marmara Region \\
\hline 26 & Male & $30-39$ & Married & Lecturer & $3001-5000 \mathrm{TL}$ & Marmara Region \\
\hline 27 & Female & $30-39$ & Single & Dr. Lecturer & $5001 \mathrm{TL}$ and above & Central Anatolia Region \\
\hline 28 & Male & $40-49$ & Married & Assoc. Prof. & $5001 \mathrm{TL}$ and above & Mediterranean Region \\
\hline 29 & Male & $30-39$ & Married & Lecturer & $5001 \mathrm{TL}$ and above & Black Sea Region \\
\hline 30 & Male & $30-39$ & Married & Assoc. Prof. & $5001 \mathrm{TL}$ and above & Aegean Sea \\
\hline 31 & Male & $30-39$ & Married & Lecturer & $5001 \mathrm{TL}$ and above & Black Sea Region \\
\hline 32 & Male & $30-39$ & Married & Dr. Lecturer & $5001 \mathrm{TL}$ and above & Aegean Sea \\
\hline 33 & Male & $30-39$ & Married & Res. Assist. & $5001 \mathrm{TL}$ and above & Central Anatolia Region \\
\hline 34 & Male & $18-29$ & Single & Lecturer & $3001-5000 \mathrm{TL}$ & Central Anatolia Region \\
\hline 35 & Male & $50+$ & Single & Assoc. Prof. & $5001 \mathrm{TL}$ and above & Mediterranean Region \\
\hline 36 & Female & $30-39$ & Married & Dr. Lecturer & $3001-5000 \mathrm{TL}$ & Central Anatolia Region \\
\hline 37 & Female & $30-39$ & Married & Dr. Lecturer & $5001 \mathrm{TL}$ and above & Eastern Anatolia Region \\
\hline 38 & Male & $40-49$ & Married & Dr. Lecturer & $5001 \mathrm{TL}$ and above & Central Anatolia Region \\
\hline 39 & Male & $30-39$ & Married & Dr. Lecturer & $5001 \mathrm{TL}$ and above & Central Anatolia Region \\
\hline 40 & Male & $30-39$ & Married & Lecturer & $5001 \mathrm{TL}$ and above & Mediterranean Region \\
\hline 41 & Female & $50+$ & Married & Dr. Lecturer & $3001-5000 \mathrm{TL}$ & Marmara Region \\
\hline 42 & Male & $30-39$ & Married & Assoc. Prof. & $5001 \mathrm{TL}$ and above & Aegean Sea \\
\hline 43 & Male & $40-49$ & Married & Dr. Lecturer & $5001 \mathrm{TL}$ and above & Marmara Region \\
\hline 44 & Female & $30-39$ & Married & Lecturer & $3001-5000 \mathrm{TL}$ & Black Sea Region \\
\hline 45 & Female & $18-29$ & Single & Res. Assist. & $3001-5000 \mathrm{TL}$ & Black Sea Region \\
\hline
\end{tabular}




\subsection{Data Collection Method}

Qualitative data collection method via metaphors was used. When metaphors are used to "describe", a situation, event and phenomenon are described as they exist (Yıldırım and Şimşek, 2013). Data from the study were collected by using a semi-structured metaphor form via survey online. In the first part of the survey, there are personal information such as Sex, Age, Marital Status, Title, Income and the Region where the university is situated. In the second part, the participants were asked to fill the sentence "Recreation is like ..... Because.........".

\subsection{Analysis of Data}

Content analysis technique was used in interpretation of data. According to Yıldırım and Şimşek (2003), the main purpose of content analysis is to reach the concepts and relations that can explain the data collected. For this purpose, data are brought together within the framework of certain concepts and themes and then they are arranged and interpreted in a way to help readers understand. The raw data obtained from the study were examined, incomplete or inexpedient ones were excluded and metaphors were modeled by transferring them to the Nvivo 10 program (Model 1). The conceptual categories were determined by 3 specialists by taking into account the justifications of metaphors (Table 2 ).

\subsection{Validity and Reliability}

Cohen's Kappa statistic is used to determine the consistency between the evaluations made by two or more encoders. Fleiss's kappa coefficient is a statistic method measuring the inter-rater reliability of comparative cohesion between more than two fixed raters (Cohen and Swerdlik, 2002). The accepted and rejected codes in the research were calculated by placing them within Cohen kappa formula.

$$
k=\frac{p_{o}-p_{e}}{1-p_{e}}
$$

The Kappa coefficient between 0.0 and .20 indicates the absence of agreement, the value between .21 and .40 denotes medium agreement, the value between .41 and .60 indicates the existence of agreement mostly, the value between .61 and .80 indicates a significant level of agreement and the value between .61 and .80 points out a high level of agreement (Landis \& Koch, 1977). The agreement between the encoders was found to be $r=0.87$ after the reliability calculation in the research. Thus, the values calculated show that there is a very good level of agreement between the raters.

\subsubsection{Ethical Clarity}

Attention and importance has been attached to the realization of the main ethical principles in this research process. In order to protect the rights of the participants providing data to the research before, during and after the research and to prevent damage;

- $\quad$ Conscious approval: The participants were asked to fill "Voluntary Approval Form" regarding their voluntary participation in the research.

- $\quad$ Privacy, respect for private life and not giving harm: The personal information of the participants were kept confidential and not uncovered.

- Cheating, deception and being loyal to data: Data obtained from the participants were expressed in the research clearly and the access to raw version of data was provided.

\section{Findings}

Table 2. Categories Related to the Metaphorical Definition of Participants about "Recreation"

\begin{tabular}{|c|c|c|}
\hline Metaphorical Definition & Categories & Participants \\
\hline $\begin{array}{l}\text { Escape, Star, Giant, Happiness (3), Music } \\
\text { Air, Freedom, Traveler, Broken Chain Ring, Octopus }\end{array}$ & $\begin{array}{l}\text { As a Value fo } \\
\text { Society }\end{array}$ & $\begin{array}{l}\mathrm{K} 1, \mathrm{~K} 3, \mathrm{~K} 6, \mathrm{~K} 11, \mathrm{~K} 15, \mathrm{~K} 18, \mathrm{~K} 19, \mathrm{~K} 21, \mathrm{~K} 24, \\
\mathrm{~K} 33, \mathrm{~K} 39, \mathrm{~K} 43\end{array}$ \\
\hline $\begin{array}{l}\text { Life, Aladdin and the magic lamp, Sun (2), Colorful } \\
\text { cake with mixed fruit, Work potential, A } \\
\text { multi-purpose field or saloon, } \\
\text { Funfair, Umbrella }\end{array}$ & Serving Needs & K9, K14, K26, K32, K38, K41 \\
\hline Flying carpet, Human & Social Reputation & $\mathrm{K} 7, \mathrm{~K} 25$ \\
\hline Aegean sea, Sea (3), Rainbow (3), Water, & Recreate & $\mathrm{K} 8, \mathrm{~K} 10, \mathrm{~K} 12, \mathrm{~K} 16, \mathrm{~K} 17, \mathrm{~K} 20$, \\
\hline
\end{tabular}

Living, Forest, Fishing tackle, Bridge, Time (2), Wind, Chameleon,K22, K23, K27, K28, K29, K30, K31, K34, K36,K37, K40, K42, Seasons, Breath, K44, K45

Science, Nature

Spice

Self-realization K13 
The categories related to the metaphorical definitions of participants on "Recreation" were created (Table 2). Some of the opinions of participants are as follows.

It is like Sun. Because it serves as a source of life for human existence. People can live in the dark, for sure but the difference between two lives i.e. the difference between sun (light) and dark can be a good example to emphasize the importance of recreation (K5).

It is like Flying Carpet. Because you feel that as if you were both in a traditional position and on a modern airplane (K7)

It is like Happiness. Because I can participate in recreation by making my own activity preference freely and using the leisure time that can be used independently (K11).

It is like Rainbow. Because its area of activity is so wide yet its field of application is different (K12).

It is like Spice. Because food can be cooked and eaten without spices. However, one of the most important elements that makes food delicious and enjoyable is the spices used. Recreation means the same thing for life. The possibilities offered by a life in which only vital requirements are fulfilled can satisfy people to a certain degree. In order to get complete satisfaction from life, it is necessary to make use of the possibilities offered by the recreation. In addition, the rich diversity of spices and the use of this variety with different combinations and proportions create an unlimited range. Recreational activities also have a power that can enrich the individual's life with unlimited variety of tastes and this power makes life enjoyable (K13).

It is like Bridge. Because it expresses innovation and renewal from a perspective. I can say that it resembles a bridge that can help the individual go from a condition (many variables such as mental, social, psychological, cognitive, spatial etc. can be counted) to another one which is desired or preferred to be (k23).

It is like Multi-purpose field or saloon. Because recreation has a multidimensional structure (K32).

It is like Science. Because, some people are constantly developing a new style of entertainment and old fun never goes away. Whenever it is needed, someone find it (K40).

It is like Octopus. Because moving freely is due to the fact that it does itself in many fields (k43).

\section{Conclusions and Recommendations}

As a result of the data obtained, the academicians working in the field of recreation use such concepts as escape, star, giant, happiness, music box, spring air, freedom, traveler, broken chain ring, octopus, life, Aladdin and the magic lamp, sun, a colorful cake with mixed fruit, work potential, a multi-purpose field or saloon, funfair, umbrella, flying carpet, human, Aegean sea, sea, rainbow, water, living, forest, fishing tackle, bridge, time, wind, chameleon, seasons, breath, science, nature and spice while describing the concept of recreation metaphorically.

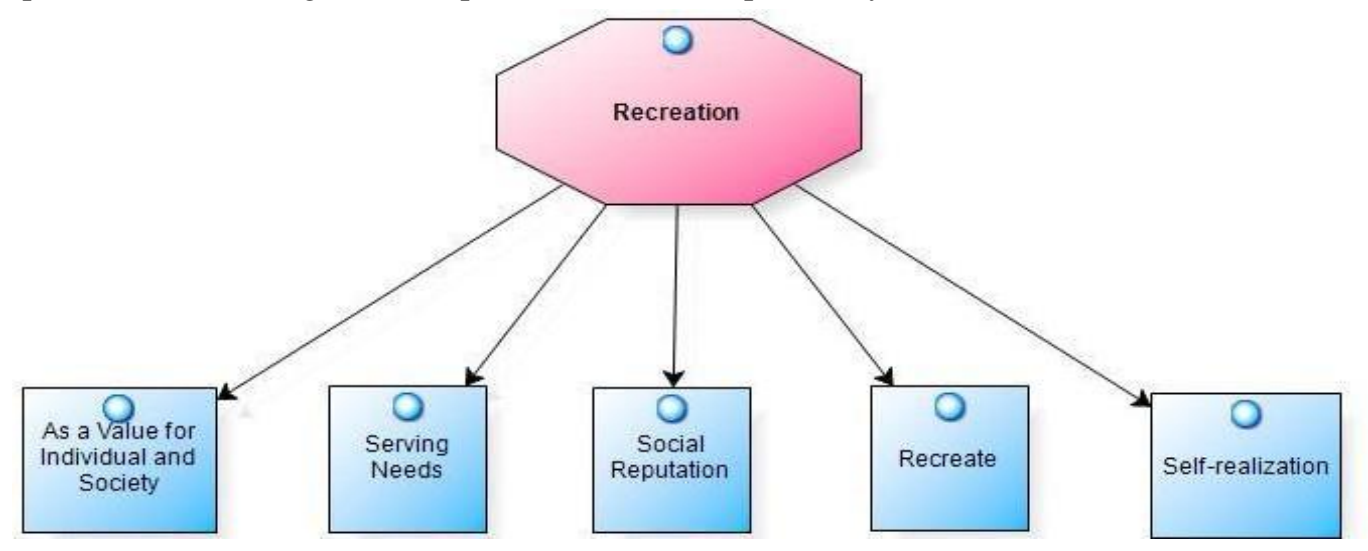

Model 1. Categorized Themes Obtained Related to the Concept of Recreation

Value for Individual and Society; With the metaphors of Escape, Star, Giant, Happiness, Music Box, Spring Air, Freedom, Traveler, Broken Chain Ring, Octopus, the theme "As a Value for Individual and Society" being one of the Recreation theories has been obtained by the opinions of participants on the concept of "recreation". According to this view, recreation provides having high emotional and social values for the well-being of the society and the individual. In this perspective, social recreation mediates the provision and protection of social cohesion and the development of social recreation depends on social inclusion (Anadolu Üniversitesi Yayınları, 2016). Individuals aim to color up their routine lives with the recreational activities they voluntarily participate in their leisure time. They participate in these activities individually or as a group. By participating in these activities, they get the opportunity to meet people from all walks of life, 
to socialize with them, to share and to learn by experience. It can be said that the leisure time which is made good use with high quality contains effective and significant process in ensuring positive contributions both for the individual and the society.

Serving Needs; With the metaphors of Life, Aladdin and the magic lamp, Sun, Colorful cake with mixed fruit, Work potential, A multi-purpose field or saloon, Funfair, Umbrella, the theme "Serving Needs" being one of the Recreation theories has been obtained by the opinions of participants on the concept of "recreation". Every individual has different needs. Recreation includes a process which serves the needs of individuals. People always demand and they take part in recreational activities in line with this demand. The need for recreational activities from personal perspective is as follows; creation of physical health development, providing mental health, socialization of individuals, creativity, development of personal skills and abilities, working success and its effect on occupational efficiency, economic mobility and making people happy. In terms of social perspective, ensuring social solidarity and integration and formation of a democratic society is among the reasons of the need for recreation (Karaküçük, 2001). According to the preferences of the individuals in line with their wishes, it is thought that the importance of recreational areas, parks, sports facilities and the services offered by the local authorities come to the forefront and the arrangements for service providing should be made by considering these needs.

Social Reputation; With the metaphors of Flying carpet and Human, the theme "Social Reputation" being one of the Maslow's hierarchy of needs has been obtained by the opinions of participants on the concept of "recreation". Individuals want to get respect from others rather than their own self-esteem in the community they live. Aktaş (2018) states that an individual with self-esteem wants to be strong, to succeed, to grow mature, to become skilled, to have self-confidence and to become free independently. People can know themselves and know new people through the recreational activities they participate and the social reputation will be stronger due to an increase in self-confidence while enjoying the activities between individuals together with the sense of achievement.

Recreate; With the metaphors of Aegean sea, Sea, Rainbow, Water, Living, Forest, Fishing tackle, Bridge, Time (2), Wind, Chameleon, Seasons, Breath, Science, Nature, the theme "Recreate" being one of the Recreation theories has been obtained by the opinions of participants on the concept of "recreation. Recreation has an important place in that children, young people, females, elderly and disabled individuals of all ages develop their self-awareness without any discrimination, they get satisfaction and pleasure, feel themselves happy and find the opportunity of renewal. Recreation is derived from the Latin word "recreatio" meaning renewal, creating from the beginning or restructuring. Recreation can be defined as the activities in which people voluntarily participate in their leisure time and get satisfaction (Yetim, 2000: 165). Stebbins (2016) defines the three basic values of leisure time activities as the desire for satisfaction (hedonism), desire for the variety of experiences created by satisfaction and individual's desire and wish to choose the leisure time activity. There is a need for recreation in every part of the society in physical, cognitive, affective and kinesthetic terms. It can be stated that it is a step for individuals to renew and realize themselves.

Self-realization; With the metaphor of Spice, the theme "Self-realization" being one of the Maslow's hierarchy of needs has been obtained by the opinions of participants on the concept of "recreation". Maslow points out that people need to focus on their goals rather than their wishes and the theories about human motivation are important in classifying people's needs (Reid Cunningham, 2008). As stated by Maslow, the self-realizing individuals satisfy their basic needs and continuously develop themselves in order to reach excellence (cited by Omay, 2010; Abukan, 2014 from Maslow). It can be expressed that self-realization of individuals in line with their knowledge and skills obtained through recreation is a significant point in maintaining their life with a high quality.

In conclusion, it is observed that regarding the metaphorical perceptions of the academicians working in the field of recreation on the concept of "recreation", the metaphors obtained comply with the recreation theories. As can be seen in this research, the concept of recreation is an important factor. In order to better understand the concept of recreation, the assessment results must be taken in applied activities.

\section{References}

Abukan, B. (2014). The relationship between wisdom and self-actualization by Maslow's hierarchy's of needs theory: a research on older people. Department of Social Work, Master Thesis, Ankara.

Aksen, A. (1984). Some basic concepts and features of outdoor recreation. Journal of Istanbul University Faculty of Forestry, 1(34), 140-149.

Aktaş, E. (2018). According to Abraham maslow's theory of needs hierarchy, consumption analysis for women today. Marmara University, Institute of Social Sciences, Public Relations Department, Department of Advertising and Publicity, Master Thesis, İstanbul. 
Brey, E. T., \& Lehto, X. Y. (2007). The relationship between Daily and Vacation Activities, Annals of tourism Research, 34(1)160-180.

Cerit, Y. (2008). Students, Teachers and Administrators' Views on Metaphors with Respect to the Concept of Principal. Education and Science, 33(147), 3-13.

Cordes, A. K. (2013). Application in recreation and leisure for today and the future. Sagamore Publishing.

Karaküçük, S. (1999). Recreation leisure time evaluation. 3. Printing. Bağırgan Bookstore.

Karaküçük, S. (2001) Recreation leisure time evaluation. 4. Printing, Gazi Bookstore, Ankara.

Karaküçük, S. (2008). Recreation leisure time evaluation. Gazi Kitabevi, (6.Baskı) Ankara.

Madrigal, R. (2006). Measuring the multidimensional nature of sporting event performance consumption. Journal of Leisure Research, 38(3), 267-292.

Öksüz, E. (2012). The evaluation leisure time activities of the students who stay both Credit and Hostels Institution of Higher Education (KYK), and the special hostels. Master Thesis, Balıkesir University, Balıkesir.

Omay, U. (2010). Evaluation of the merchant class in support of the protestant movement in terms of Maslow's needs hierarchy approach. Journal of Social Politics Conferences, 52.

Reid-cunningham, A. R. (2008). Maslow's theory of motivation and hierarchy of human needs: A critical analysis. Unpublished doctoral dissertation, Berkeley University of California, Berkeley, California.

Rızvanoğlu, K. (2007). The cross-cultural understanding of the metaphors in the graphical user interfaces (a comparative study in France and Turkey on an e-learning site) PhD thesis. Marmara University, Institute of Social Sciences, Istanbul

Stebbins, R. A. (2016). The idea of leisure time Basic principles (Translated by M.Demirel., N.E.Ekinci., Ü.D.Üstün., U.Işı1k and O. Gümüşgül) 1. Printing., Spor Publisher., Ankara

Torkildsen, G. (2005). Leisure and Recreation Management.5th ed. London: Routledge.

Tütüncü, Ö. (2012). The Role of Recreation and Recreation Therapy in Quality of Life. Anatolia: Journal of Tourism Research, 23(2), 248-252.

Yetim, A. (2000). Sociology and Sports. Ankara: Topkar Printing, 160-170.

\section{Copyrights}

Copyright for this article is retained by the author(s), with first publication rights granted to the journal.

This is an open-access article distributed under the terms and conditions of the Creative Commons Attribution license which permits unrestricted use, distribution, and reproduction in any medium, provided the original work is properly cited. 